\title{
March Madness in the Collegiate Sport Workplace: Cultural Implications for Sport Employees
}

\author{
Brent D. Oja and Rammi N. Hazzaa \\ University of Northern Colorado \\ Zachary Wilkerson and Jordan R. Bass \\ University of Kansas
}

\begin{abstract}
Drawing upon Schein and Schein's three-level conceptual framework of organizational culture, the purpose of this study was to examine how organizational culture and a sense of community manifest within intercollegiate athletics departments during March Madness. Considering the popularity of intercollegiate sport and March Madness, it is important for scholars to understand how organizational culture may influence the attitudes and behaviors of collegiate sport employees in the workplace. Thus, semi-structured interviews and observations were conducted to better understand how culture, community, and the phenomenon of March Madness traverse. Analysis of the data revealed a unique organizational culture within intercollegiate athletics departments, distinguishing them from other nonsport organizations. It was also discovered that socialization processes occur during March Madness, which can foster a sense of community. Implications for these findings are discussed and practical recommendations for collegiate athletics departments are provided.
\end{abstract}

Keywords: organizational behavior, organizational culture, sense of community

In 1996, the National Collegiate Athletic Association (NCAA) licensed the use of "March Madness" to describe the NCAA tournament, after CBS sportscaster Brent Musburger used the expression to refer to the NCAA men's basketball tournament (Bowman, 2015). Over time, the madness has grown, and in 2010 CBS Sports and Turner Broadcasting agreed to a \$10.8-billion-dollar deal to broadcast every tournament game until the year 2024. The popularity and success of the tournament has largely been impacted by the popularity of bracket pools. For example, in 2015 an estimated 70 million people participated in tournament bracket pools, where individuals speculate on the winners of each contest before

Oja and Hazzaa are with the University of Northern Colorado, Greeley, CO. Wilkerson and Bass are with the University of Kansas, Lawrence, KS. Address author correspondence to Brent D. Oja at brent.oja@unco.edu. 
the tournament begins (Berr, 2015). While entertaining and popular nationally, it is estimated that this March distraction contributes to \$134 million in lost wages during the tournament (Sanburn, 2013) and a productivity loss for businesses estimated close to $\$ 1.9$ billion in 2015 (Berr, 2015).

These previous examinations have been focused on the quantitative aspects of this phenomenon in the workplace and have not specifically focused on a group of workers who may be especially distracted during March Madness: collegiate sport employees. This examination is necessary as the sport environment is unique when compared with other nonsport industries (Chalip, 2006). Past examinations of collegiate sport employees have included, among other things, job satisfaction (Cunningham, Fink, \& Sagas, 2005; Kim, Magnusen, Andrew, \& Stoll, 2012), identification (Oja, Bass, \& Gordon, 2015), and organizational power incongruities (Oja \& Bass, 2016). While some scholars have begun the process of investigating collegiate sport employees, little is known of such employees' cognitive processes and subsequent behaviors. When examining collegiate sport employees, it is important to consider both organizational culture and the construct known as sense of community due to their prevalent roles in influencing employee attitudes and behavior. Organizational culture has been described as a product of shared learning that guides behaviors of members and, specifically, the " . . accumulated learning is a pattern or system of beliefs, values, and behavioral norms that come to be taken for granted as basic assumptions and eventually drop out of awareness" (Schein \& Schein, 2017, p. 6). As organizations prosper, their culture influences not only behavior, but also "a language, a way to think, and a way to feel" (Schein \& Schein, 2017, p. 9).

Sense of community is a construct that is thought to impact intercollegiate athletics departments and their stakeholders (Warner \& Dixon, 2011). Sense of community, the interdependence and feeling of acceptance to a group (Sarason, 1974), could influence collegiate sport employees' perceptions of their organizations' culture during March Madness due to the propensity for membership to promote shared learning, values, beliefs, and norms. Therefore, the purpose of this study is to better understand how organizational culture and a sense of community materialize within intercollegiate athletics departments during March Madness. We have utilized March Madness - a germane event for intercollegiate athletics departments - to assist in diagnosing a sense of community and organizational rituals, values, and basic assumptions. Rituals seem to have a particularly prominent role in the development of a culture. Intercollegiate athletics departments utilize rituals such as prep rallies, bonfires, and ceremonial functions (e.g., awards banquet) to build and sustain organizational culture (Beyer \& Hannah, 2000; Charlton, 2011). The need for such research is rooted in collegiate sport employee and organizational development. Specifically, intercollegiate athletics departments could improve the functionality of the organization with a better understanding of the ramifications associated with an enhanced cohesiveness within the workplace during March Madness. Designing a positive organizational culture or improving the sense of community can function as a method to inhibit potential negative employee outcomes (Schein, 2010; Warner \& Dixon, 2011). For instance, the failure of organizational culture to prohibit harmful college sport employee conduct can enable counterproductive work behavior (e.g., watching games instead of working), which is a form of workplace deviance that counteracts 
the organizational culture and disregards the values, norms, and beliefs of the organization (Robinson \& Bennett, 1995). It is also possible that the rituals associated with March Madness in intercollegiate athletics departments, whether or not they are counterproductive to productivity, might benefit the organization and its employees due to the unique environment in which such organizations exist.

\section{Literature Review}

\section{Organizational Culture}

Myriad definitions exist for the concept known as organizational culture (Schein \& Schein, 2017). Uttal (1983) regarded organizational culture as a system of shared values (i.e., what is important) and beliefs (i.e., how things work) that interact with an organization's people, structures, and control systems to produce behavioral norms (i.e., the way we do things around here). Schein and Schein (2017) described how cultures create standard behaviors and attitudes in response to turbulence from the organization's environment. An organizational culture is also developed through leadership practices. Scholars have shown that organizational culture is positively associated with leadership (Schein, 2010), in addition to morale and teamwork (Goffee \& Jones, 1996). Leaders are ultimately the decision makers and have control over shaping the organization's values, and what behaviors they choose to accept and reinforce (Schein, 2010).

One of the conceptual frameworks utilized for this study was influenced by Edgar Schein (i.e., Schein, 2010; Schein \& Schein, 2017). This framework was chosen in order to identify the organizational culture experienced by collegiate sport employees. In this framework, an organization's culture exists on a continuum of levels that progress from tangible to intangible. These levels include artifacts (level one), espoused values and beliefs (level two), and basic underlying assumptions (level three). The artifacts level consists of physical and visible representations of an organization's culture. Relevant examples of artifacts include observable ceremonies and rituals. For example, rituals can be observed during March Madness in the form of bracket competitions and watch parties. Rituals have been viewed as social instruments used to establish community identity and collective representations of an organization (Durkheim, 1915/1961). Artifacts and rituals have been empirically shown to be physical representations of organizational culture in both public (Mahler, 1997) and private (Barnes, Jackson, Hunt, \& Kumar, 2006) industries, as well as intercollegiate athletics departments (Charlton, 2011). The importance of rituals lies with the constant visibility (i.e., tangibility) of prescribed tenets dictated by organizational leadership (Schein \& Schein, 2017), which provide reinforcement for appropriate behaviors. In turn, rituals can be effective tools in reinforcing desired values and performance amongst employees (Higgins \& McAllaster, 2002; Hogan \& Coote, 2014; Smith \& Stewart, 2011).

The espoused beliefs and values level represents a shift from tangible to intangible culture. Yet, beliefs and values “... remain conscious and are explicitly articulated because they serve the normative or moral functioning of guiding members of the group..." (p. 20) in their behavior (Schein \& Schein, 2017). 
The beliefs and values of an organization are a philosophical direction for members or guidance on what should be done in a given situation. Moreover, these beliefs are discussed and reinforced with adherence. The last level, basic underlying assumptions, symbolizes unconscious yet powerful guidance. Underlying assumptions embody dogmas that are so intertwined with the functioning of an organization that they are unquestioned. Unsurprisingly, such conviction requires a substantial degree of verification before acceptance; however, once assumed, their effect is potent. "Cultures tell their members who they are, how to behave toward each other, and how to feel good about themselves" (Schein \& Schein, 2017 , p. 23). In this way, the underlying assumptions level of organizational culture is a deep-seeded standard so pervasive that it guides behavior and attitude without analysis.

The culture of intercollegiate athletics departments has become a popular topic of discourse and has been viewed as a critical function within the collegiate sport setting (Beyer \& Hannah, 2000). Burton and Welty Peachey (2014) utilized culture as a mediator to help explain leadership's influence on work outcomes in the intercollegiate sport setting. The authors found group culture partially mediated the relationship between leadership and affective organizational commitment, while fully mediating the relationship with turnover intentions and job search behaviors. Developmental culture also partially mediated the relationship between leadership and affective commitment but had no influence on the other variables. Others have found that transformational leadership, coupled with transparent communication and college sport employee participation, were important factors that intercollegiate athletics department leaders can utilize to improve organizational culture (Welty Peachey, Bruening, \& Burton, 2011). Subcultures (e.g., coaches, sports, department units) within intercollegiate athletics departments have also been examined, and it was discovered that they have the ability to approve, enhance, or challenge the assumptions of entire departments (Southall, Wells, \& Nagel, 2005). Culture change within an intercollegiate athletics department has also been investigated. It has been revealed that value congruency is an influential factor for acceptance of a culture change (Welty Peachey \& Bruening, 2012). In terms of generating a positive culture, it was determined that policies and rituals were significant contributors (Charlton, 2011). To assess the culture of an intercollegiate athletics department, examining institutional culture, and internal and external environments have been prescribed (Schroeder, 2010). However, it appears that a gap in the literature still exists. This gap is particularly noticeable in terms of investigations into how intercollegiate athletics departments' cultures are predisposed by a major sport event such as March Madness.

\section{Sense of Community}

A second conceptual framework for this study is known as sense of community (SOC), theorized as a "conceptual cousin" (Kerwin, Warner, Walker, \& Stevens, 2015, p. 78) to social capital, and originally developed by Sarason (1974). Specifically, Sarason defined SOC as:

The perception of similarity to others, an acknowledged interdependence with others, a willingness to maintain this interdependence by giving to or doing for 
others what one expects from them, the feeling that one is part of a larger dependable and stable structure. (p. 157)

Scholars have since condensed the definition of SOC to "a feeling that members have of belonging and being important to each other, and a shared faith that members' needs will be met by their commitment to be together"' (Chavis, Hogge, McMillan, \& Wandermans, 1986, p. 11). Although the theory has been predominantly utilized in community and neighborhood development (e.g., Berkman, Glass, Brissette, \& Seeman, 2000; Chavis \& Wandersman, 1990; Davidson \& Cotter, 1991), SOC has also been applied to other contexts, including sport (e.g., Kerwin et al., 2015; Warner \& Dixon, 2011, 2013, 2016; Warner, Dixon, \& Chalip, 2012; Warner, Kerwin, \& Walker, 2013). Warner and Dixon (2013) recalled Gusfield's (1975) position that community can represent geographical areas and relationships contextualized as a shared interest to explain the multifaceted functionality of SOC. Specifically, SOC has been operationalized to explain relational processes of sport personnel in sport organizations (Warner et al., 2013), and is especially applicable to intercollegiate athletics departments (Warner \& Dixon, 2011).

Despite utilization in a variety of environments, Warner and Dixon (2016) have supported the applicability of SOC in the sport setting and have argued that sport represents "one of the few remaining social institutions that foster a sense of community in our society" (p. 49; Warner, Dixon, \& Leierer, 2015; Warner et al., 2013). For example, scholars have used sport as a mechanism to better understand the SOC amongst referees (e.g., Kellet \& Warner, 2011). Other scholars have examined community formation between sport fan groups (e.g., Katz \& Heere, 2013; Yoshida, Gordon, Heere, \& James, 2015; Yoshida, Heere, \& Gordon, 2015) and student fans (e.g., Clopton, 2009). Sport volunteerism (e.g., Kerwin et al., 2015), youth sport parents (Warner et al., 2015), and seasonal employee retention (e.g., McCole, Jacobs, Lindley, \& McAvoy, 2012) have also been investigated.

The specific deployment of SOC within the sport setting has been advanced with the development of multiple factors, which provide a deeper understanding of the construct (Warner et al., 2013). Several of those factors are particularly relevant to intercollegiate athletics departments and major sport events such as March Madness. These include social spaces that foster social interaction (e.g., watch parties), competition (e.g., tournament brackets), and a common interest in sport. College sport employees are thought to have an interest in athletics (Oja et al., 2015). It stands to reason that when a popular event (e.g., March Madness) occurs during normal work hours, then those with a sport interest (i.e., college sport employees) will watch the sport event. Such an occurrence may improve collegiate sport employees' sense of community by creating shared experiences and reinforcing connections between employees. In light of the previous literature, we propose the following research questions:

RQ1: How do rituals reflect intercollegiate athletics departments' cultures during March Madness?

RQ2: How do espoused values and beliefs emulate intercollegiate athletics departments' cultures during March Madness? 
RQ3: What are the basic underlying assumptions that manifest in intercollegiate athletics departments' cultures during March Madness?

RQ4: How is a sense of community interrelated with the organizational culture of an intercollegiate athletics department during March Madness?

\section{Method}

To better comprehend the organizational culture in intercollegiate athletics departments and the influence of sense of community, qualitative methods were deemed to be the most appropriate. The qualitative methods provided a detailed description of circumstances that have seen few examinations (i.e., March Madness; Smith \& Caddick, 2012). To gather data, the researchers used semi-structured interviews and observations. This allowed the researchers to gather deep and rich descriptions from the participants (Smith \& Caddick, 2012). Semi-structured interviews are “... a standard set of questions, or schedule. However, the researcher adopts a flexible approach to data collection, and can alter the sequence of questions or probe for more information with subsidiary questions" (Jones, 2015, p. 177). Such interviews rely on conversing with the participants by asking questions and listening (Kvale, 1996; Rubin \& Rubin, 2005).

To better elucidate how organizational culture and a sense of community emerge in intercollegiate athletics departments during March Madness, observations of athletics department employees during the first week of the event were conducted. The observations allowed for the recording of behaviors of collegiate sport employees in their natural work setting. They also served as a mechanism to critique socially desirable answers from participants by comparing interviews to their behaviors recorded during the observations. This second source of data also functioned as a triangulation method by confirming the self-reported data (i.e., interviews) from the participants (Jones, 2015).

\section{Participants}

The recruitment of participants involved the utilization of the researchers' professional contacts and their recommendations. This resulted in 21 collegiate sport employee interviews via purposive sampling, by which participants are chosen "because they possess certain characteristics or traits" (Jones, 2015, p. 129). Additionally, four collegiate sport employees from one university- three of which were interviewed-were observed during March Madness. Accessibility limited the observations to one university. Participants were selected due to their employment status with various American collegiate athletics departments in different roles. These roles included positions in various departments such as: fundraising and development, compliance, marketing, equipment operations, and event operations. Participants were qualified based on their experience working in college athletics departments that are eligible for NCAA Division I championship events. To retain the anonymity of the participants due to potentially sensitive topics (e.g., lack of productivity), selective demographic information was recorded and pseudonyms were assigned. Five of the 21 interviewees were female and were assigned gender-neutral pseudonyms. 


\section{Procedure}

Before the interviews and observations took place, institutional review board approval was obtained. The interviews were audio recorded and then transcribed. Participants were read a list of questions that evolved throughout the interviews. Follow-up questions were asked as needed. Interviews took place approximately 1 month after the championship game and were conducted until data saturation was achieved. Questions were open-ended in order to allow the participants to expand upon their answers and provide rich data (Smith \& Stewart, 2001).

Four athletics department employees were observed by author one during the first week of March Madness, as this week represented the only week of the event where contests took place during normal work hours. The participants signed consent waivers before the observations occurred. In light of the informed consent, an observer as participant stance was utilized to perform the observations (Jones, 2015; Merriam, 1998). The observations took place throughout normal workhours during each day of the week. This resulted in multiple observations every workday (i.e., Monday through Friday), which fluctuated from two to six visits per day based on the observational procedures and the availability of the participants. Generally, observations early in the week were shorter to help the participants become used to being observed, to build rapport between author one and the participants, and for author one to become familiar with the setting (Merriam, 1998). As the week progressed, observations were more frequent and their length increased, which also coincided with the apex of March Madness. This allowed for observations on normal workdays as well as days enmeshed with March Madness. The duration of the observations lasted from $10 \mathrm{~min}$ (e.g., Monday) to over $60 \mathrm{~min}$ (e.g., Friday) per visit to an office. Author one would enter the participant's office space and observe during standard work hours. At times, conversations would arise, some of which were relevant to March Madness and others not. Author one would move from office to office at varying times that were determined by the workload of the participants. Author one recorded field notes during the observations when possible, often times while moving from one office to another. At the end of each day, author one added greater detail to the recorded field notes.

\section{Researcher Positionality}

It is relevant to acknowledge the impact of how author one's background as a collegiate sport employee influenced this investigation (Giardina \& Newman, 2011). Such a background can improve the "critical representation of ourselves within our research" (Misener \& Doherty, 2009, p. 466). The first author was a collegiate sport employee at four different universities over a 6-year time period. He witnessed and felt the cultural experiences of sport employees who work at the intercollegiate level. Many of the standardized questions were based on those experiences in addition to relevant literature. These experiences likely provided the opportunity to collect unique and powerful data from the participants.

\section{Instrument}

Based on previous literature (e.g., Schein, 2010; Schein \& Schein, 2017; Warner \& Dixon, 2011, 2013) and the background of author one, a standard set of questions 
for the interviews was created. These questions served as a starting point for the semi-structured interviews. Examples of the questions included: (a) How is March Madness viewed around the office? (b) Would you be considered an outsider, or something like one, if you did not watch the games of March Madness at work? Why or why not? (c) How do you socialize with your coworkers during March Madness? (d) How often did you have the tournament games on your computer or TV during work hours? (e) Does less work get done around the office during March Madness? (f) Would you feel comfortable if your supervisor saw you watching the games during work hours?

\section{Analysis}

To begin the process of analyzing the data from both the interviews and the field notes from the observations, open coding was used (Strauss \& Corbin, 1990). Strauss and Corbin (1990) created this strategy to code grounded theory endeavors, but previous scholars have utilized open coding in nongrounded theory studies (e.g., Schaeperkoetter, Bass, \& Gordon, 2015; Schaeperkoetter et al., 2017). This procedure is also supported by Corbin and Strauss (2008), as they noted that:

The distinctions between the two types of coding (axial and open) are 'artificial' and for explanatory purposes only, to indicate to readers that though we break data apart, and identify concepts to stand for the data, we also have to put it back together again by relating those concepts. (p. 198)

Moreover, the technique of integrating interview transcripts and observational field notes, has been used by recent scholars (e.g., Gordon \& Arney, 2017). Strauss and Corbin (1990) explained: “. . in open coding, event/action/interaction, and so forth, are compared against others for similarities and differences; they are also conceptually labeled. In this way, conceptually similar ones are grouped together to form categories and subcategories" (p. 423). The procedure to code the data relied on Jones' (2015) four-part coding framework. For the first stage, the authors independently read the interview transcripts and ascribed codes (i.e., summation of response) to all responses. This is known as open coding. The second stage, axial coding, involved rereading the data and searching for representative statements that fit with the established codes. The third stage called for the authors to "become more analytical and look for patterns and explanation in the themes" (Jones, 2015, p. 278). To do so, the authors collectively analyzed the open codes and discussed how deductive themes were related to previous theory, and how inductive themes should be positioned to emphasize the unique findings from the data. For the final stage, selective coding, the authors reviewed the raw data in order to locate representative quotes of the themes. Additionally, the authors examined the quotes gathered from stage two to determine their applicability to previous theory that was selected in stage three. When disagreements existed between the authors in regard to coding, they were discussed until agreement was reached.

\section{Trustworthiness}

In order to ensure the trustworthiness of the study, the researchers utilized Shenton's (2004) four criteria (i.e., credibility, transferability, dependability, 
and confirmability). The credibility criterion was assessed with four of Shenton's specific provisions, which were (1) the adoption of well-established qualitative research methods, (2) triangulation, (3) tactics to help ensure honesty in informants, and (4) the background, qualifications, and experience of the researcher(s). Observations and interviews are prominently featured by Jones (2015) in his descriptions of data collection methods. Further, the specific methods used were guided by established procedures. The use of two separate methods-interviews and observations - allowed for triangulation. All participants voluntarily agreed to partake in the study and were provided with informed consent documents, which notified them of their answers being anonymous and encouraged honest answers. The background of author one, as detailed in the researcher positionality section, was provided to the participants before data collection and likely aided in the building of camaraderie between author one and the interviewees (Shenton, 2004).

Other strategies described by Shenton (2004) were used to certify transferability, dependability, and confirmability. The transferability of the study was supported with descriptions of the March Madness phenomenon, sense of community, organizational culture, and contemporary intercollegiate athletics department culture examinations to enable comparisons. For dependability, a detailed account of the procedure utilized in the study is provided. The detailed description of the study will support the replication of the study to other sport environments. Lastly, for confirmability, triangulation was utilized with two forms of data collection, and the Limitations and Future Directions section contains various shortcomings of the study and their possible implications (Shenton, 2004).

\section{Results}

The results of the analysis of the data revealed two primary themes. Those themes were related to intercollegiate athletics department culture and sense of community. Additionally, there were secondary themes that emerged from the data. Each subtheme addresses various research questions. In the first primary theme, the buzzing office theme provides information supporting RQ1 (i.e., rituals) and RQ3 (i.e., basic assumptions). The acceptance theme has information concerning RQ2 (i.e., values and beliefs) and RQ3. The approval theme also supports RQ2. The sense of community primary theme has a secondary theme (i.e., connecting within the office) that helps to answer RQ1, as well as secondary themes (i.e., connecting within the office, connecting outside the office, and implications for those who do not watch sports) that address RQ3 and RQ4 (i.e., interrelation of sense of community and organizational culture).

\section{Intercollegiate Athletics Department Culture}

A broad theme emerged from the data that constituted a semblance of a general intercollegiate athletics department culture that was exemplified during March Madness. The following are distinct themes that epitomized the intercollegiate athletics department culture.

The buzzing office. Participants reiterated the word "buzz" on many occasions. A palpable level of excitement was felt by collegiate sport employees during the 
basketball games of March Madness. Ben mentioned: "You can't [sic] beat it, especially when your team is in it." John agreed: "It is absolutely more fun if your team is in it." When asked about how things are different around the office, Dave explained: "The first whole half of the day you hear people up and down the hallway talking about the previous night's games." Interestingly, a lack of participation by the athletics department's team did not preclude excitement. Mike explained: "We can pick a team and cheer for them for the day. It is pretty fun." Many of the participants described how the games of March Madness were viewed as a "reward" for all of their hard work during the year. Mike added: "It is a celebration for all the work that we put in through the year. Even if our team is not in it, it is still a very good time for college athletics as a whole." Alex clarified: "I think we [college sport employees] all look forward to this time of year. A lot of people talk about them [games] before and after and take a lot of interest." Mark described how the office ". . . is business as usual, but there is an added excitement to it, especially if the team you work for is in it [March Madness], people get more engaged."

Participants also provided various rationale for the increased excitement. Jeff explained: "Sports is drama, and there is a lot of drama in March Madness. That is a reason to be excited about everything going on and a raised level of enjoyment." Fred illuminated how the excitement of March Madness captured engrossed and casual fans alike and how, "all of the sudden, once March Madness comes around, everybody is sticking their chests out and supporting their alma maters or know what time they are playing or who they are playing against." Later, Fred provided a unique circumstance related to past success:

If you have high expectations of going [to the NCAA tournament] and you don't [sic] make it, I think it can certainly be very crushing, and hard to deal with. People can get fired for not making the tournament. But, especially for a team that hasn't [sic] made it in a few years, everyone gets super excited. With our team making it the past few years, we are starting to see the reverse effect. We made it again this past year ... and you see people get complacent with it. When we were at the selection show [as a department], the first couple of years everyone is excited, jumping up and down, and now it is like no big deal because we were a three seed. You didn't [sic] see the general enthusiasm as you did the first couple of years, where people were much more excited about it.

Generally, the games were viewed as a time to relax and enjoy the spectacle of sport.

The buzzing office was apparent during observations. On Monday, one participant detailed their plan to watch as many games as possible during work hours. This involved utilizing a work station with a computer screen for one game, one of the participant's two customary monitors for viewing a different game, and the other for work-related activities. When asked about their plans for March Madness, participants' eyes would light up, smiles formed, and enthusiastic responses would follow. During Thursday and Friday, participants consistently provided one another with score updates, along with commentary. When a game failed to go to overtime, one participant was despondent: "They only needed to go 
for two [points]!" In a similar instance, cheers and shocked faces were the result of one team completing a game tying three-point basket only to lose the game seconds later. At the conclusion of that game, the participants searched for the next closest game to entertain themselves. The buzzing office theme helps to address both RQ1 (e.g., the ritual of watching games) and RQ3 (e.g., assumed excitement).

Acceptance. The ritual of watching March Madness games was generally accepted and normalized by the participants. For example, Fred described how "there is a lot of people taking a long lunch or two-hour break or have it on the TV [sic]. I would say the vast majority of the people [college sport employees], I know I certainly do [watch games during work hours]." This theme is a representation of the notion that collegiate sport employees are likely to stay involved with sport when possible. Bob exemplified the importance of staying connected with sport and competition: "People who work for athletics departments do it because they love it [competition] and for people who work in athletics, competition comes pretty hand in hand." The meaningfulness of competition for collegiate sport employees was also recorded during observations. For example, the athletics department had a traveling trophy that went from office to office depending upon performance, which represents a specific ritual of that organization's culture. The participants explained that March Madness and working in an intercollegiate athletics department are compatible and it would be "odd" if they did not watch the games during March Madness. John described how offices "shut down for two and a half hours. A lot less work probably gets done. Just walk around and you will see a lot of computer monitors turned on to a game." Alex explained that:

I definitely do a lot less work, especially when the teams that I was really cheering for [were playing] because it is really hard to have the game on one screen and work on the other. It is really hard to focus. I personally try to use those days to get really mundane stuff done that I hadn't [sic] done in a while, so I could still focus on who was playing. I am sure a lot of people do that.

Tom justified completing less work by indicating such behavior was accepted by his peers:

I do think some people get a lot of their work done prior to those days. I have [a game] on one of my two computer screens and I know a lot of other staff does the same. We are talking and thinking about it. You work in sports, why would you not have it on? I think it is [acceptable]. It is a lifestyle and when you live and breathe it, it is part of the territory. It is just a couple of days and times of the year. It is kind of known and everybody is on the same page. You get what you need to get done, and you move forward from there.

Kelly echoed Tom's thoughts on working ahead and the regularity of less work occurring: "I think it is pretty normal. [I] would probably work harder to get work done earlier in the day. I still think work is done whether those [games] are going on or not." Timothy also sensed that work was still being accomplished: "One screen may have the game up while doing work. I think people are still pretty productive at work. You have to be locked in to what you're [sic] doing." 
Paul noted that their giant video board in the area had the games on for athletics department employees to watch. Jeff stated:

Given the fact that we work in athletics, it is acceptable to have the sports on. We have a TV [sic] in our office, I try to not make it the focal point, and if work is not being done it needs to be turned off.

Many participants said that they had two computer screens, one of which would have the March Madness games on. This was described as a "probably acceptable" behavior by Mackenzie and Cole. Mackenzie later provided a representative quote: "We work in sport, so it's pretty acceptable [to have the games on]". During the observations, most of the participants watched the games during work hours. Participants were not bashful, if not blatant, concerning their viewing of the games. However, participants did highlight the importance of completing work while watching the games. The observed participants were consistently working and would describe having the games on as "background noise". Participants would monitor events within the games, to different degrees, but were concurrently working on various projects. Some would take breaks roughly every 15 min to check scores, while others constantly had games on their computer screens. Interestingly, one participant remarked that "everyone is tweeting about how they are working right now", referring to other colleagues and how conscious they were about demonstrating their work ethic. Yet, the practice of watching the games was seemingly accepted based on the transparency of participant viewership. In all, the acceptance theme provides answers for RQ2 (e.g., value of working) and RQ3 (e.g., assumed acceptance of watching sport).

Approval from supervisors. The participants explained that their supervisors supported the ritual of watching March Madness during work hours. Supervisors would not reprimand their employees, and some actually facilitated the viewing of the contests. Paul, who had mentioned the video board showing the games, said that his supervisor was the one to put the games on for the athletics department employees to watch. Cole remarked that they were "one hundred percent comfortable" if their supervisor saw them watching March Madness games and, as Keith noted, "[supervisor] more than likely would have joined [in watching]." Alex shared this sentiment as the supervisor's reaction was likely to be: "... who are you watching or what is happening in the game? They might come over and peek at my computer to see the score."

During the observations, it was not uncommon for coworkers or even supervisors to stop at an office and ask for an update from a game. One participant exhibited no concern of admonishment by smiling and lightly laughing at the notion of their boss observing employees watching the games. Bob remarked that he would feel comfortable if his supervisor saw him watching the games during work and that it is "going to happen. I don't [sic] think it is disrespectful to the institution to have it [games] on as long as you are doing your work. If my boss came in, chances are they might want to know a score." John provided further rationale: "We work at lot, we work hard, so as long as you are getting your work done, I don't [sic] think my supervisor would care. They know if you work in athletics, you probably watch athletic events." Alan stated that he was very comfortable with his supervisor seeing him watch the games during work: 
"He has them on too, but if things are not getting done, it would probably be different." The feeling of total acceptance was not universal. Tom mentioned that, "it took a few years to get comfortable [with my supervisor]" with the thought of being seen watching games during work hours. Mark said that he would be nervous and that, "obviously we are not getting paid to watch March Madness", and this feeling was a result of the mood set by his superior. Ben summarized the differences between leadership in sport and other businesses:

If I was working at a real business, not very comfortable at all. I would be terrified. Here we are all yelling at each other to make sure that if we are watching one game to turn the other game on. My boss... she is just right there with us.

The approval from supervisors theme helps to answer RQ2 by emphasizing how the values and beliefs of the intercollegiate athletics departments were shaped by leadership.

\section{Sense of Community-Coming Together as a Department}

Participants explained how the March Madness event had ramifications on community formation and thus organizational culture. The sense of community in intercollegiate athletics departments appeared to be grounded in having an interest in sports. As such, there was a general sense that those collegiate sport employees who do not enjoy sport or are not as passionate about sport as others might struggle to align with their organization's culture.

Connecting outside of the office. Participants explained that the bonds formed in the office from the shared interest in sport-specifically March Madnesscarried over to activities (i.e., rituals) outside of the work environment. These rituals included gathering to watch the games during the lunch hour at a local dining establishment, or meeting at an employee's residence after work to watch the games. Tim explained: "This year our university was in the tournament so there was a lot of media around and more people going to bars to watch the games." Mike described external gatherings:

We gathered around, some our staff, and we all went out to eat during the opening rounds and we were watching some of the games together. We do that quite a bit anyways, but March Madness is a reason to go out and have a beer and talk about the games or watch the games. Everybody gets along pretty well. Especially in our sector of the office, we can go out and grab dinner and stuff on weekends or after work. It is a pretty tight knit community with our department.

According to Cole, meeting outside of work "definitely builds camaraderie." James explained how watching games with coworkers is a "socialization process", and Ben noted that "it can bring people together who don't [sic] normally have a conversation over 99 topics and couldn't [sic] stand to be in the same room, but then you put a game on and those people ... find common ground in sports." This theme was also noted during the observations. On Monday, when looking over the slate of games and the timing of Saint Patrick's Day, one participant proclaimed, 
“That's [sic] trouble!", inferring that it was unlikely they would remain in the office for an extended period of time on that day. This theme was also acutely pertinent on Friday afternoon, specifically just after lunch. Employees made plans to watch the evening games together at a local pub, and asked each other, "When are you getting out of here?". The connecting outside the office theme provided information that addressed RQ3 and RQ4 by reinforcing the basic assumption of a sport interest and discovering that the sense of community extended beyond the boundaries of the workplace.

Connecting within the office. Beyond gathering outside of the office, participants also remarked on how the events of March Madness functioned to unite them with other athletics department employees within the confines of the work environment. One ritual that was repeatedly mentioned was office watch parties, where the organization would provide an opportunity for employees to gather with the express intention of watching their representative team perform. These rituals would not occur unless the team representing the organization was participating in the event at a time that overlapped with regularly scheduled work hours. John stated:

You better believe there were a lot of watch parties going on. If you play a game during the day, basically the entire athletics department would shut down and would offer a watching session in a meeting room and have food and drinks, and watch the game and go back to work [after the game ended].

Alan mentioned how administrators "invite everybody down for it, to come and at least view it for at least your lunch hour, and I think that is a pretty cool thing." Further, these events enabled athletics department employees to interact with each other. Bob stated:

I think just having something else to talk about other than the monotonous stuff of every day [helps]. I think it just brings an athletic department together almost in a way where you're $[\mathrm{sic}]$ talking to people about what upset will happen and I think that is pretty cool.

Tom referred to internal gatherings for March Madness as “. . . a fun bonding experience. To talk to your co-workers and have a little fun with it."

Another aspect of community formation was the ritual of filling out March Madness brackets and turning the activity into a competition. Mark described how important the brackets were to his colleagues: "We did a bracket challenge and the winner gets a trophy ... it is something that people can get behind. You can have those conversations at the water cooler, and I think it brings people closer together." Yet, the motivation for participating in a bracket competition was not cohesive. Timothy noted that while many are excited to fill out brackets and talk about upcoming games, others are likely " ... just doing it because the rest of the office is." During the early portion of the first week of March Madness, observed participants filled out their brackets, sometimes comparing their brackets with fellow employees' brackets. One participant was involved in a bracket competition with collegiate sport employees from a different university. This ritual represented a tangible point of connection and facilitated the building of 
comradery. The connecting within the office theme supported the answering of RQ1 and RQ4 by emphasizing the importance of rituals such as watch parties and how such rituals supported the sense of community.

Implications for those who do not watch sports. While many athletics department employees appeared to enjoy or even revel in the excitement of March Madness, this was not true for all coworkers of the participants. Those individuals who did not partake in the ritual of watching games were thought to not fit in well with their fellow employees, especially during the month of March. Jamie remarked that they "may tease them [nonwatchers] a little bit." Steve was more forward: "I think that [they would] definitely be viewed as someone who doesn't $[s i c]$ play along and getting into it and being part of the culture." Timothy was even more forceful:

In the athletics department, you have an unwritten responsibility to be in touch with what is going on around you, if you are working with teams directly. If you don't [sic] have an interest in sports or have a sense of what is going on around you, you would definitely be an outsider.

Jeff used a different label rather than outsider: "It would be almost crazy to want to work in this field and not have a draw towards sports. It is what our lives revolve around to some level. You would be considered an odd ball, not necessarily an outsider." Alan suggested a possible implication for a lack of sport interest: "... you would probably not fit in well and be treated differently, and probably not get invited to a lot of [outside the office] events." Sam explained that it was a "weird thing" when they encountered an athletics department employee who did not like sports. Sam went on: "I think it's more stranger [sic] personally if someone just doesn't $[$ sic $]$ like sports overall and worked in athletics, they probably won't [sic] work in athletics long." Dave described how some would "roll their eyes" in the direction of such a college sport employee. Fred provided a potential explanation for the lack of sport interest in that those who work in the business office are not as connected with those who work closely with the teams and "the majority of their work is almost unathletic [sic] related, they are not connected or feel valued from a direct sports program".

Participants were not unified in their perceptions of implications for those who did not watch the games of March Madness. Although some participants noted the potential for exclusion, others disagreed with that assessment. John used himself as an example by describing how consumed with work-related issues he is throughout the year and his lack of concentration on March Madness. John later conceded that he is likely in the minority:

At any school that I've [sic] worked at, if you walk around during March Madness you're [sic] going to see different people with games on, you're [sic] going to see people looking at their phones, checking scores ... I don't [sic] think anyone would particularly care if an individual wanted to work instead [of watching games]. Would it be surprising? Sure. Would they be considered an outsider? I don't necessarily know about that.

Mark rationalized the importance of work capability: "As long as your work is up to par and exceeding, I don't [sic] think anyone gets judged on that." 
Kelly remarked that, "I know there are people in our office that don't [sic] care at all and don't [sic] watch [sports], but they are not treated any differently just because they don't [sic] know who won or lost last night." This sentiment was found to be true during the observations. While no direct observations of athletics department employees who completely avoided March Madness occurred, it was not uncommon for individuals to meet with participants to go over organizational business. These meetings were not met with ridicule or consternation even if they took participants away from watching the games. Instead, business generally proceeded as usual, despite a decrease in productivity. It appeared that the athletics department was not completely consumed with March Madness. The theme of implications for those who do not watch sports addressed RQ3 and RQ4 by offering information related to the prominence of sport and to the boundaries of the community.

\section{Discussion}

We sought to answer four research questions: how rituals reflect intercollegiate athletics departments' cultures during March Madness (RQ1), how espoused values and beliefs emulate intercollegiate athletics departments' cultures during March Madness (RQ2), what are the basic underlying assumptions that manifest in intercollegiate athletics department's cultures during March Madness (RQ3), and how a sense of community is interrelated with the organizational culture of an intercollegiate athletics department during March Madness (RQ4). The culture of intercollegiate athletics departments described by the participants can be explained with a three-level framework (Schein, 2010; Schein \& Schein, 2017). The first level is recognized with tangible artifacts and rituals, which have been found to be critical components of intercollegiate athletics department culture (Charlton, 2011). With regard to RQ1, conversations and observations unveiled several rituals and artifacts. The most prominent ritual involved watching the games of March Madness, whether that was in a group setting (i.e., watch party) or individually. The buzzing office theme is a representation of the ritual's importance to organizational members. Participants noted the ritual's cultural significance by explaining how it was eagerly anticipated, its enjoyableness, and the degree to which it positively impacted the organization socially. The ritual's inducement of such emotions underscores the more tangential (i.e., espoused values and basic assumptions) aspects of Schein and Schein's (2017) organizational culture paradigm, as rituals are derived from deeper suppositions. Restated, watching the games of March Madness was a conspicuous projection of an intercollegiate athletics department culture.

The watch party ritual also served as a social space (Swyers, 2010; Warner et al., 2013) for increased interactions between college sport employees. Attendance at watch parties was not mandatory, but did allow those with an interest in the games an opportunity to socialize. Social spaces constitute safe locations for community members (Warner \& Dixon, 2011) to behave in a socially accepted manner, which is defined by the organizational culture. The social space (i.e., watch party ritual) allowed the participants to celebrate an occasion that is deemed to be reflective of the organizational culture (Schein \& Schein, 2017). 
Interestingly, watch parties only commenced if a representative team was participating. Thus, the culture within intercollegiate athletics departments differs from professional- or community-sport-based organizations, as it is unlikely that other sport organizations would hold an official function whereby employees would stop working and watch a sporting contest. In the collegiate sport environment, such a ritual is valued. More specifically, this ritual is an allusion to the significance that intercollegiate athletics departments assign to sport and competition.

Another ritual consisted of filling out tournament brackets and competing with colleagues. While this is a ritual that is likely practiced in nonsport organizations, one of the unique aspects for intercollegiate athletics departments are the resulting artifacts from various competitions. Two examples of trophies as artifacts were discovered. One organization had a trophy that was awarded to the winner of their bracket competition. Also, during the observations it was revealed that the organization utilized a "traveling trophy", which was bestowed to high performing units. This is similar to a ritual that is celebrated in college sport: traveling trophies that are vied for predominately by football teams. In fact, the observed ritual was inspired by the collegiate football tradition. The relevance of these rituals is the fortification of sport. That is, such rituals further entrenched the organization with pertinent characteristics of sport (i.e., emphasis and glorification of competition).

RQ2, the second level of culture-espoused values and beliefs-was exemplified by participants' and their supervisors' conscious efforts to maintain professionalism in the midst of watching the games. Participants articulated that, while it was still acceptable to watch the games, it was critical to complete work assignments and to remain professional. A trepidation of the perception that college sport employees are simply a collection of athletes with few professional skills was evident. Despite these concerns, the participants still took part in various rituals that detracted from professional responsibilities. Collegiate sport employees appear to visibly demonstrate their professionalism via behaviors and appearance, and simultaneously retain a belief that the norms of their industry permit sportrelated rituals and artifacts that obfuscate professionalization. These findings signify a dichotomy for college sport employees. Some college sport employees yearn to assimilate with prototypical business roles and behaviors, and yet many participants acknowledge that working for an intercollegiate athletics department is distinctive from nonsport organizations. This distinction was in the form of prescribed behaviors (i.e., watching games) that would otherwise be not acceptable at "real jobs". The dichotomy of professionalism and uniqueness of working in the collegiate sport environment appears to be a matter of restrained or pseudo professionalization, whereby standardization and labor are coveted, but deviation from a strictly professionalized environment (e.g., acceptance of watching games) is also valued. As such, the dichotomy of collegiate sport employee professionalization might be partially explained via the organizational environment. The NCAA consistently reinforces the narrative of all competitions being amateur in nature. Perhaps this mantra could contribute to a belief that working in collegiate sport is, at some level, less professional. This finding further supports the importance of value congruency (i.e., degree of professionalization) within an intercollegiate athletics department culture (e.g., Welty Peachey \& Bruening, 2012). The collegiate sport workplace appears to be a unique environment due, in part, to the presence of this dichotomy. 
Another aspect of the second level of culture was the influence of leadership. Leaders establish rules and procedures for organizations, which help to formulate an organizational culture (MacIntosh \& Doherty, 2008). Leaders' influence over an intercollegiate athletics department culture had been previously supported (e.g., Burton \& Welty Peachey, 2014; Welty Peachey et al., 2011). Furthermore, the power of leadership is prominent at the espoused values and beliefs level (Schein, 2010; Schein \& Schein, 2017). Values that come specifically from leadership are a means to create normative behavior (Schein \& Schein, 2017). Participants expressed that viewing games during March Madness was supported by their supervisors, such as when the games were put on a large video board. Supervisors also facilitated this process by organizing various rituals (e.g., watch parties), watching the games themselves, or asking for game updates from their subordinates. By perpetuating such behaviors, college sport supervisors engrained the viewing of March Madness into the values of an intercollegiate athletics department's culture. Professional- and community-based sport organizations are likely to have divergent values and goals from their collegiate counterparts. Professional sport organizations are enterprises that are designed to maximize profits for ownership, and likely have less tolerance for a loss of productivity during March Madness. Community-based sport organizations generally promote participation and holistic approaches to sport. Yet, in an intercollegiate athletics department environment, competition is valued (Beyer \& Hannah, 2000), as seen in the current study by the proliferation of opportunities to watch the games of March Madness and the sanctioning of bracket contests. An emphasis on competition might run counter to the norms of professional- and community-based programs, as such sport organizations might place a greater value on concepts such as worker productivity or member participation in various sports.

RQ3, the third level of organizational culture, consists of underlying assumptions, which are characterized as norms that are so strongly interwoven with the organizational culture that they are not questioned, but instead are implicit (Schein $\&$ Schein, 2017). The previously mentioned bracket competition ritual helped to reveal support for an interest in sport and competition as a basic assumption. The behavior of participating in bracket contests is particularly noteworthy due to the gambling restrictions placed on collegiate sport employees by the NCAA. The only form of a bracket competition that a collegiate sport employee could participate in, without jeopardizing their career, are those without monetary reward. Consequently, it appears that collegiate sport employees participated in bracket competitions due to their attraction to competition and sport. The acceptance of watching games theme similarly revealed an underlying assumption of an interest in sport and competition. The sport interest of collegiate sport employees was exemplified with its use as justification to watch games during work hours. Generally, participants explained that having an interest in sport was expected and it would be aberrant to not have a sport interest, and some characterized it as a responsibility.

This produces a deeper quandary: Are collegiate sport employees fans of their employers' teams or do they simply enjoy sport and competition? The results are an indication of the latter, as most of the participants noted the general excitement surrounding the event. The excitement was not predicated on a representative team's participation, though some did note that this intensified the experience. Rather, the excitement was a result of the amplification of valued constructs-sport 
and competition-within their specific work environment. Though not a specific study of collegiate sport employees, Oja, Bass, and Gordon (in press) found that sport employees identified with sport and competition as part of their cognitive affiliation with their sport organization, which supports the emphasis on sport and competition instead of teams. The resonance with sport and competition, then, provides the genesis for an intercollegiate athletics department culture and consequently stimulates the more tangible forms of culture (e.g., watch party ritual).

As for RQ4, the community gatherings that took place outside of the workplace were bolstered by the college sport employees' shared interest in sport and competition, as it was the driving force for the assemblies. The emphasis on the shared interest in sport and competition reinforces previously hypothesized (Oja et al., 2015) and discovered (Kellett \& Warner, 2011) results. Moreover, the strength of the participants' interest in sport transcended physical workplace boundaries to external meeting locations. The congregations outside of the intercollegiate athletics department represent a culture that reached beyond the focal gathering setting. That is, participants' culture, reinforced by their sense of community, transferred from one physical location to another. It was the community characteristic (i.e., underlying assumption of interest in sport and competition; Sarason, 1974) that influenced the sense of community and organizational culture-not the physical manifestation of the community (i.e., workplace). Due to the presence of a community, March Madness created a unique opportunity to further engrain the values of the organizational culture. It is possible that sport employees in other sport organizations (e.g., professional and community based) also gather to watch sporting events. However, intercollegiate athletics departments have a multitude of teams that have employees who work specifically with a team, unlike having one team that represents the entire organization. By gathering inside and outside of the workplace and developing a sense of community, collegiate sport employees are afforded the opportunity to reinforce cultural norms with those who they seldom interact with due to different team responsibilities.

By participating in bracket competitions, athletics department employees similarly engendered more opportunities to converse (i.e., comparing brackets and strategies) with their colleagues, which may have contributed to an additional benefit of an improved sense of community. Competition is thought to be an integral part of forming a sense of community (Warner \& Dixon, 2011, 2013; Warner et al., 2013). Competition has also had mixed results when applied to investigations of various sport organizations (see Kerwin et al., 2015; Warner \& Dixon, 2011, 2013). Kerwin et al. (2015) posited that sport volunteers' sense of community was not supported through competition due to a lack of participation in the event. We have surmised that college sport employees' sense of community was enhanced by competition. The enhancement occurred in two mannerscompetition due to palpable participation in bracket contests and the emphasis on competition by intercollegiate athletics departments (Beyer \& Hannah, 2000).

While the previously mentioned findings of the study are of a positive intercollegiate athletics department culture, there was the discovery of a potentially adverse reaction to collegiate sport employees who do not share an interest in sport and competition. Some participants indicated that a disinterest or aversion from sport would interfere with or even prevent socialization with members. Given the 
seemingly pertinent implications of an interest in sport and competition, lacking such an attraction would work against the very core of the culture. As previously stated, contextual factors create communities, and the integration of counter ideologies would be a detriment to a community. Then, it is not surprising that participants were hesitant or even unwilling to allow entry to potential members deemed to be oppositional, and others only assimilated with group norms (e.g., participating in bracket contests) to improve their standing in the organization. For those college sport employees without the requisite interest in sport and competition, there is a risk of isolation - an antithesis to sense of community (Kellett \& Warner, 2011; Warner \& Dixon, 2013). Schein and Schein (2017) conveyed that those who fail to align with the basic underlying assumptions of an organization's culture (i.e., sport interest) endanger their membership. This concept is known as social validation and "means that certain beliefs and values are confirmed only by the shared social experience of a group" (Schein \& Schein, 2017, p. 20). In this setting, that belief is the importance of sport and competition, and those who do not share this belief are in danger of expulsion. Although the occurrence of disinterested collegiate sport employees was thought to be rare, the potential remains for negative workplace ramifications such as isolation or turnover.

In summation, intercollegiate athletics departments appear to foster a unique culture, as demonstrated by the discovery of a basic assumption of having an interest in sport and competition. This is a product of the distinctive environment in which intercollegiate athletics departments exist (Beyer \& Hannah, 2000). Specifically, intercollegiate athletics departments value competition as all teams fiercely compete with their opponents, while professional teams are focused on profit maximization (sometimes employing "tanking" maneuvers to purposely lose games; Soebbing, Humphreys, \& Mason, 2013), and community-based programs strive to improve the experiences of their members. The theoretical contribution of this work is the discovery of a unique intercollegiate athletics department culture, which is perpetuated by an interest in sport and competition. The culture is realized via a dichotomy of a pseudo professionalism of collegiate sport employees and reinforcement from leadership. The various rituals, which inculcate the culture, involved gatherings supported by the established community to watch sport events and assorted competitions.

The results of this study also contained practical implications. Culture is partially dependent upon the members of an organization. The social interactions and exchanges of staff members are fundamental to the value of a culture because it creates a sense of belonging and purpose (MacIntosh \& Doherty, 2008). Collegiate sport administrators may consider increasing opportunities for their employees to interact in a sport setting to improve comradery. Ritualistic activities (e.g., March Madness watch parties) are a source of significant social and organizational advantages to membership, such as bringing people together, forming close-knit bonds, and communicating important values (Smith \& Stewart, 2011). Engaging in such activities might allow athletics department employees to ultimately improve their productivity because they are collective actions that reinforce social solidarity and highlight an organization's behavior (Durkheim, 1915/1961; Smith \& Stewart, 2011). Thus, collegiate sport administrators might consider being more accommodating of counterproductive work behaviors during March Madness. As Robinson and Bennett (1995) surmised, a counterproductive work behavior typically works 
against the organizational culture. However, in intercollegiate athletics departments, the prevailing culture reinforced the lack of productivity. Although many of the participants noted support from their supervisors, those collegiate sport supervisors who are less tolerant of decreased work efficiency could improve organizational morale by supporting watch parties or similar rituals.

\section{Limitations and Future Directions}

The nature of qualitative research prevents an assumption of generalizability. While unique themes were discovered during the study, it would be inappropriate to assume these themes prevail throughout all intercollegiate athletics departments. The observations were conducted after informed consent was granted, so the participants might have conducted themselves in a socially acceptable manner. This may have prevented the researchers from gathering data that reflected true behaviors of collegiate sport employees. The observations took place at one athletics department, which also limits generalizability. The sample population included five females and 16 males, which could have skewed the findings to lean to a male perspective.

Scholars should next look to better define fandom in the sport workplace. While outside of the scope of this study, a specific and perhaps unique form of fandom might play an important role in the behaviors of collegiate sport employees. A deeper analysis of professionalization and fandom within the collegiate sport workplace is a potential next step in this line of research. Beyond investigations of the fandom of collegiate sport employees, the application of emerging constructs, such as psychological capital (Kim, Perrewé, Kim, \& Kim, 2017) on collegiate sport employees, may prove to be beneficial. As discovered in this study, collegiate sport employees represent a unique workgroup with distinct rituals, norms, assumptions, and group awareness, whereby different psychological processes (e.g., fandom and psychological capital) might impact the overall intercollegiate athletics department.

\section{References}

Barnes, J.W., Jackson, D.W., Jr., Hutt, M.D., \& Kumar, A. (2006). The role of culture strength in shaping sales force outcomes. Journal of Personal Selling \& Sales Management, 26(3), 255-270. doi:10.2753/PSS0885-3134260301

Berkman, L.F., Glass, T., Brissette, I., \& Seeman, T.E. (2000). From social integration to health: Durkheim in the new millennium. Social Science \& Medicine, 51, 843-857. PubMed ID: 10972429 doi:10.1016/S0277-9536(00)00065-4

Berr, J. (2015, March). Businesses are bracing for March madness. CBSNews.com. Retrieved from http://www.cbsnews.com/news/businesses-are-bracing-for-marchmadness/

Beyer, J.M., \& Hannah, D.R. (2000). The cultural significance of athletics in U.S. higher education. Journal of Sport Management, 14, 105-132. doi:10.1123/jsm.14.2.105

Bowman, E. (2015, March). March madness: Keeping society sane since 1908. NPR.org. Retrieved from http://www.npr.org/2015/03/15/392764016/five-fun-facts-about-marchmadness-fan-culture

Burton, L.J., \& Welty Peachey, J. (2014). Organizational culture mediates the relationship between transformational leadership and work outcomes. Journal of Intercollegiate Sport, 7, 153-174. doi:10.1123/jis.2013-0070 
Chalip, L. (2006). Toward a distinctive sport management discipline. Journal of Sport Management, 20, 1-21. doi:10.1123/jsm.20.1.1

Charlton, R. (2011). The role of policy, rituals and language in shaping an academically focused culture in HBCU athletics. Journal of Issues in Intercollegiate Athletics, 4, $120-148$.

Chavis, D.M., Hogge, J.H., McMillan, D.W., \& Wandersman, A. (1986). Sense of community through Brunswick's lens: A first look. American Journal of Community Psychology, 14, 24-40. doi:10.1002/1520-6629(198601)14:1<24::AID-JCOP 2290140104>3.0.CO;2-P

Chavis, D.M., \& Wandersman, A. (1990). Sense of community in the urban environment: A catalyst for participation and community development. American Journal of Community Psychology, 18, 55-81. doi:10.1007/BF00922689

Clopton, A. (2009). Students as spectators: Their academic and social integration. New Directions for Higher Education, 2009(148), 83-89. doi:10.1002/he.371

Corbin, J., \& Strauss, A. (2008). Basics of qualitative research: Techniques and procedures of developing grounded theory (3rd ed.). Thousand Oaks, CA: Sage.

Cunningham, G.B., Fink, J.S., \& Sagas, M. (2005). Extensions and further examination of the job embeddedness construct. Journal of Sport Management, 19(3), 319-335. doi:10.1123/jsm.19.3.319

Davidson, W., \& Cotter, P.R. (1991). The relationship between sense of community and subjective well-being: A first look. Journal of Community Psychology, 19(3), 246-253. doi:10.1002/1520-6629(199107)19:3<246::AID-JCOP2290190308>3.0.CO;2-L

Durkheim, E. (1915/1961). The elementary forms of the religious life (trans. J.W. Swain). New York, NY: Collier Books.

Giardina, M.D., \& Newman, J.I. (2011). What is this "physical" in physical cultural studies? Sociology of Sport Journal, 28(1), 36-63. doi:10.1123/ssj.28.1.36

Goffee, R., \& Jones, G. (1996). What holds the modern company together? Harvard Business Review, 74(6), 133-148.

Gordon, B.S., \& Arney, J. (2017). Investigating the negative fan behaviors of a branded collegiate basketball student section. Journal of Amateur Sport, 3(2), 82-108. doi: 10.17161/jas.v0i0.5714

Gusfield, J.R. (1975). The community: A critical response. New York, NY: Harper Colophon.

Higgins, J.M., \& McAllaster, C. (2002). Want innovation? Then use cultural artifacts that support it. Organizational Dynamics, 31(4), 74-84. doi:10.1016/S0090-2616(02)00073-6

Hogan, S.J., \& Coote, L.V. (2014). Organizational culture, innovation, and performance: A test of Schein's model. Journal of Business Research, 67, 1609-1621. doi:10.1016/ j.jbusres.2013.09.007

Jones, I. (2015). Research methods for sport studies. New York, NY: Routledge.

Katz, M., \& Heere, B. (2013). Leaders and followers: An exploration of the notion of scalefree networks within a new brand community. Journal of Sport Management, 27, 271-287. doi:10.1123/jsm.27.4.271

Kellett, P., \& Warner, S. (2011). Creating communities that lead to retention: The social worlds and communities of umpires. European Sport Management Quarterly, 11(5), 471-494. doi:10.1080/16184742.2011.624109

Kerwin, K., Warner, S., Walker, M., \& Stevens, J. (2015). Exploring sense of community among small-scale sport event volunteers. European Sport Management Quarterly, 15(1), 77-92. doi:10.1080/16184742.2014.996581

Kim, M., Perrewé, P.L., Kim, Y., \& Kim, A. (2017). Psychological capital in sport organizations: Hope, efficacy, resilience, and optimism among employees in sport (HEROES). European Sport Management Quarterly, 17(5), 659-680. doi:10.1080/ 16184742.2017.1344284 
Kim, S., Magnusen, M., Andrew, D., \& Stoll, J. (2012). Are transformational leaders a double- edged sword? Impact of transformational leadership on sport employee commitment and job satisfaction. International Journal of Sports Science \& Coaching, 7(4), 661-676. doi:10.1260/1747-9541.7.4.661

Kvale, S. (1996). Interviews: An introduction to qualitative research interviewing. Thousand Oaks, CA: Sage Publications.

MacIntosh, E., \& Doherty, A. (2008). Inside the Canadian fitness industry: Development of a conceptual framework of organizational culture. International Journal of Sport Management, 9(3), 303-327.

Mahler, J. (1997). Influences of organizational culture on learning in public agencies. Journal of Public Administration Research and Theory, 7(4), 519-540. doi:10.1093/ oxfordjournals.jpart.a024364

McCole, D., Jacobs, J., Lindley, B., \& McAvoy, L. (2012). The relationship between seasonal employee retention and sense of community: The case of summer camp employment. Journal of Park \& Recreation Administration, 30, 85-101.

Merriam, S.B. (1998). Qualitative research and case study applications in education. San Francisco, CA: Jossey-Bass Publishers.

Misener, K., \& Doherty, A. (2009). A case study of organizational capacity in non-profit community sport. Journal of Sport Management, 23(4), 457-482. doi:10.1123/jsm.23. 4.457

Oja, B.D., \& Bass, J.R. (2016). Safety or style? An examination of the role of football equipment personnel. Journal of Applied Sport Management, 8(1), 26-45. doi:10. 18666/JASM-2016-V8-I1-6211

Oja, B.D., Bass, J.R., \& Gordon, B.S. (2015). Conceptualizing employee identification with sport organizations: Sport Employee Identification (SEI). Sport Management Review, 18(4), 583-595. doi:10.1016/j.smr.2015.02.002

Oja, B.D., Bass, J.R., \& Gordon, B.S. (in press). Identities in the sport workplace: Development of an instrument to measure sport employee identification. Journal of Global Sport Management, 1-37. doi:10.1080/24704067.2018.1477521

Robinson, S., \& Bennett, R. (1995). A typology of deviant workplace behaviors: A multidimensional scaling study. Academy of Management Journal, 38, 555-572.

Rubin, H.J., \& Rubin, I.S. (2005). Qualitative interviewing: The art of hearing data. Thousand Oaks, CA: Sage.

Sanburn, J. (2013). March madness will cost businesses $\$ 134$ million. Why aren't employers concerned? Time.com. Retrieved from http://business.time.com/2013/03/19/marchmadness-will-cost-businesses-134-million-why-arent-employers-concerned/

Sarason, S.B. (1974). The psychological sense of community: Prospects for a community psychology. San Francisco, CA: Jossey-Bass.

Schaeperkoetter, C.C., Bass, J.R., \& Gordon, B.S. (2015). Student-athlete school selection: A family systems theory approach. Journal of Intercollegiate Sport, 8(2), 266-286. doi:10.1123/jis.2015-0003

Schaeperkoetter, C.C., Oja, B.D., Mays, J., Krueger, K., Hyland, S., Christian, R., \& Wilkerson, Z. (2017). The "new" student-athlete: An exploratory examination of scholarship eSports players. Journal of Intercollegiate Sport, 10(1), 1-21. doi:10.1123/ jis.2016-0011

Schein, E.H. (2010). Organizational culture and leadership. Hoboken, NJ: John Wiley \& Sons.

Schein, E.H., \& Schein, P. (2017). Organizational culture and leadership. Hoboken, NJ: John Wiley \& Sons.

Schroeder, P.J. (2010). A model for assessing organizational culture in intercollegiate athletic departments. Journal of Issues in Intercollegiate Athletics, 3, 98-118. 
Shenton, A.K. (2004). Strategies for ensuring trustworthiness in qualitative research projects. Education for Information, 22(2), 63-75. doi:10.3233/EFI-2004-22201

Smith, A., \& Stewart, B. (2001). Beyond number crunching: Applying qualitative techniques in sport marketing research. The Qualitative Report, 6. Retrieved from http:// www.nova.edu/ssss/QR/QR6-2/smith.html

Smith, A.C., \& Stewart, B. (2011). Organizational rituals: Features, functions and mechanisms. International Journal of Management Reviews, 13(2), 113-133. doi:10.1111/ j.1468-2370.2010.00288.x

Smith, B., \& Caddick, N. (2012). Qualitative methods in sport: A concise overview for guiding social scientific sport research. Asia Pacific Journal of Sport and Social Science, 1, 60-73. doi:10.1080/21640599.2012.701373

Soebbing, B.P., Humphreys, B.R., \& Mason, D.S. (2013). Exploring incentives to lose in professional team sports: Do conference games matter? International Journal of Sport Finance, 8(3), 191-207.

Southall, R.M., Wells, D.E., \& Nagel, M.S. (2005). Organizational culture perceptions of intercollegiate athletic department members. The Applied Research in Coaching and Athletics Annual, 20, 65-93.

Strauss, A., \& Corbin, J. (1990). Basics of qualitative research: Grounded theory procedures and techniques. Newbury Park, CA: Sage.

Swyers, H. (2010). Wrigley regulars: Finding community in the bleachers? Champaign, IL: University of Illinois Press.

Uttal, B. (1983). The corporate culture vultures. Fortune, 108(8), 66-72.

Warner, S., \& Dixon, M.A. (2011). Understanding sense of community from the athlete's perspective. Journal of Sport Management, 25, 257-271. doi:10.1123/jsm.25.3.257

Warner, S., \& Dixon, M.A. (2013). Sports and community on campus: Constructing a sports experience that matters. Journal of College Student Development, 54(3), 283-298. doi: $10.1353 / \mathrm{csd} .2013 .0044$

Warner, S., \& Dixon, M.A. (2016). Connecting it all: Creating community in sport and entertainment. Sport \& Entertainment Review, 2, 45-50.

Warner, S., Dixon, M.A., \& Chalip, L. (2012). The impact of formal versus informal sport: Mapping the differences in sense of community. Journal of Community Psychology, 40(8), 983-1003. doi:10.1002/jcop.21506

Warner, S., Dixon, M.A., \& Leierer, S. (2015). Using youth sport to enhance parents' sense of community. Journal of Applied Sport Management, 7, 45-67. doi:10.18666/JASM2015-V7-I4-5994

Warner, S., Kerwin, S., \& Walker, M. (2013). Examining sense of community in sport: Developing the multidimensional 'SCs' scale. Journal of Sport Management, 27, 349-362. doi:10.1123/jsm.27.5.349

Welty Peachey, J., \& Bruening, J. (2012). Are your values mine? Exploring the influence of value congruence on responses to organizational change in a division I intercollegiate athletics department. Journal of Intercollegiate Sport, 5, 127-152. doi:10.1123/jis.5.2.127

Welty Peachey, J., Bruening, J., \& Burton, L.J. (2011). Transformational leadership of change: Success through valuing relationships in a football championship subdivision athletic department. Journal of Contemporary Athletics, 5(2), 127-152.

Yoshida, M., Gordon, B., Heere, B., \& James, J. (2015). Fan community identification: An empirical examination of its outcomes in Japanese professional sport. Sport Marketing Quarterly, 24(2), 105-119.

Yoshida, M., Heere, B., \& Gordon, B. (2015). Predicting behavioral loyalty through community: Why other fans are more important than our own intentions, our satisfaction, and the team itself. Journal of Sport Management, 29, 318-333. doi:10.1123/ jsm.2013-0306 